\title{
A Multidimensional Development Study of Written English Complexity of High-level Non-English Major Students
}

\author{
Yazhen Guo ${ }^{1} \&$ Haiyuan Chen ${ }^{1}$ \\ ${ }^{1}$ Jiangxi Normal University, China \\ Correspondence: Yazhen Guo, Jiangxi Normal University, China
}

Received: November 21, 2019

Accepted: December 25, 2019

Online Published: December 26, 2019

doi: 10.5539/elt.v13n1p156

URL: https://doi.org/10.5539/elt.v13n1p156

This study is financially supported by the Jiangxi Provincial Education Reform Project (Grant No.JXJG-17-2-36).

\begin{abstract}
Writing is widely regarded as one of the most important parts in the field of second language learning and teaching. The main assessment elements of L2 writing can be divided into accuracy, fluency and complexity. The evaluation of writing, accuracy, fluency and complexity can not only measure the writing achievement of L2 writers, but also reflect their writing ability. Based on the complexity of writing, this study adopts the dynamic system theory to investigate the multidimensional development of written English complexity. Three sophomores of high-level non-English majors in a university are selected as subjects to track the development and interaction patterns of eight linguistic complexity indices in 21 essays over three semesters at three levels: lexical construction, sentence construction and phrase construction. The results show that the change and development of subjects in this respect are not linear, but there are peaks, troughs, progress and regression. The development of written language has obvious dynamic and variability.
\end{abstract}

Keywords: written English complexity, high-level students, non-English major, construction

\section{Introduction}

How learners develop their mastery of language is a core issue in second language acquisition field. Writing proficiency is an important indicator to assess learners' language proficiency. Complexity, fluency and accuracy of Language are the criteria to measure learners' language proficiency (Skehan 2009; Ellis \& Barkhuizen 2005). In recent years, more and more researchers (such as Yuan \& Ellis 2003; Larsen-Freeman 2006), from different perspectives, studied the complexity, accuracy and fluency of learners' language proficiency.Among them, the concept of "complexity" has become a basic parameter to measure second language proficiency (Bulte \& Housen 2012). Bulte \& Housen (2012) points out that despite existing research, More than 40 indicators have been used to measure linguistic complexity, but different studies has their own understanding of linguistic complexity. This study conducted a three-semesters follow-up survey of three high-level non-English majors in a university, aiming at finding the developmental characteristics of written English complexity from three constructions, eight perspectives.

\section{Literature Review}

\subsection{Defining Dynamic System Theory}

Dynamic System Theory (DST) is emerging in the field of linguistics Theoretical genre. The first application of DST to study second language acquisition is attributed to Diane Larsen Freeman who published an article in 1997. The theory holds that the language system has the characteristics of self-organization, adaptation, complexity and openness. (Thelen \& Smith 1994; van Geert 1994; Herdina \& Jessner 2002; Larsen-Freeman 2002), language development is dynamic, non-linear, chaotic and unpredictable (Port\&van Elder 1995; Steenbeek \& van Geert 2007; De,Bot 2008; Larsen-Freeman \& Caeron 2008). DST provides theoretical support for the study of language learning and language development processes. The dynamics of language learning can be explained from two aspects: (1) Language learning is not a process of simply acquiring fixed language forms and rules, but a process of constantly adjusting its own language resources to adapt to different contexts. (2) It's the small changes in everyday language use that make up the catastrophic changes. Variability is seen as the core 
of DST research, and longitudinal case studies are typical methods for studying variability. Among the various variability studies, the most methodological significance is Verspoor et al's (2008). In his research, he followed a three-year English academic writing of a Dutch student with a high level of English proficiency, resulting in multiple sets of data on word diversity and sentence complexity and word diversity to describe learner's English development. The research results show that: (1) the level of writing is always changing, and in a non-linear development situation, progress and regression alternate with each other; (2) Nonlinear development is related to learner' internal changes(such as the initial stage, learning strategies, IQ, etc.). Based on DST, Larsen-Freeman (2006) studied the complexity, fluency, and accuracy of five Chinese English learners' language (including written and spoken language) over a six-month period. Through quantitative analysis, It is found that: (1) The development of language complexity, fluency and accuracy of learners is generally on the rise, individuals got different kinds of development trajectories. (2) The development of the three aspects within the individual is nonlinear, no obvious relevance, accompanied by large fluctuations and regression phenomena. Through qualitative analysis, Larsen-Freeman found that Individual development has different characteristics, learners' motivation and personal experience have a great impact on their development. Zheng Yongyan(2018) collected 128 writings from 16 English major freshmen in a year to study free output vocabulary. Through various analysis methods of dynamic system theory. It turns out that the development of learners' free output vocabulary is leaping, phased and non-uniform.

From the above-mentioned studies, we can see that DST emphasizes a case-based diachronic study in the study of learners' language development. It is very important to analyze individual patterns and understand the degree of variability at the individual level. Therefore, in order to find out the characteristics of the language development path of English learners, the study carried out three semesters dynamic follow-up study on the development of three students' written English complexity.

\subsection{Defining Construction}

The original meaning of "construction" is "architectural" and "construction", that is, two or more components are grouped together into one larger unit, and later has the meaning of "construction". Traditional grammar works borrow the word to describe the language structure.Before the construction grammar was officially born as a theoretical method, there were already some ideas in the linguistic works. Constructivism treats construction as a symbol, and not only has its form but its own meaning. In ancient Greek grammar theory, language is the "symbolic reaction of psychological process". Language units are considered to be form-meaning correspondence. (Robins 1951: 25-26). Whether they are morphemes, sentences or language structures which contains meanings or discourse functions, all of them can be considered as construction. The construction reflects the cognitive categorization process and processing mechanism in the process of human language processing. Therefore, language development is the result of the interaction of multiple factors(Goldberg,2003).Since inline interactions are sometimes generated between smaller constructions and more complex constructions, different types of reference ranges should be expanded to focus on the interaction between the constructions(Wang Chuming 2015).

This study divides the construction into three levels: sentence construction, lexical construction and phrase construction, trying to examine the development of written language complexity of high-level non-English majors.

\section{The Present Study}

\subsection{Research Question}

How does written English complexity change over 3 semesters?

\subsection{Research Subject}

The subjects of the study are 3 sophomores from non-English majors in the same university of Jiangxi province who are taught from one teacher. At the beginning of the study, all grades of students' writings and final test were checked, and then here were some high-level students. Among these high-level students, three of them were picked who all wrote the 7 writings on "pigai" network. 21 compositions in total are collected.

\subsection{Data Collection}

The study lasted three semesters. At the end of the third semester, 21 compositions were collected. All the compositions are chosen under the class practices based on output-oriented method. After submitting the composition, the writings from "pigai" network and the relevant information were exported into the computer. 
The title of the composition(see Table 1).

Table 1.

\begin{tabular}{lll}
\hline The 1st & How Science Changes Our Lives & 2017.12 .21 \\
The 2nd & The Ways of Learning in the Middle School and in university & 2018.3 .18 \\
The 3rd & My view on the material things ( money, wealth, possessions) & 2018.4 .1 \\
The 4th & My view on the virtual world & 2018.4 .27 \\
The 5th & Women, half the sky. Agree or Disagree? & 2018.6 .16 \\
The 6th & I will build my dream life in ...( the city or the country) & 2018.9 .22 \\
The 7th & Give Thanks to & 2018.12 .4 \\
\hline
\end{tabular}

From the chart, the first writing was assigned in the first semester. From the 2nd writing to the 5th writing, they were assigned in the second semester. The last second writings were assigned in the third semester.

\subsection{Linguistic Measures}

\subsection{1 measures of lexical construction}

There are three measuring indexes in the study of lexical construction: lexical density(LD), lexical diversity(Uber) and lexical sophistication(LS). Web-based L2 Lexical Complexity Analyzer is used to calculate lexical density and lexical diversity. It's a computational system that was Lu Xiaofei for automatic analysis of lexical and syntactic complexity in L2 writing. The validity has been verified, because it has been used to analyse writing complexity in many times(eg. Khany \& Kafshgar 2016, Mazgutova \& Kormos 2015). Uber index formula is used to analyse lexical diversity. This formula provides a relatively accurate measure of lexical diversity and is independent of the length of the text (Dewaele, 1993; Tweedie\&Baayen). A software called Range 32 to measure lexical sophistication(LS). The original data package in the program Range 32 contains 3 categories: BASEWORD 1 list, BASEWORD 2 list and BASEWORD 3 list. BASEWORD 1 list contains first 1000 most frequently word family. BASEWORD 2 list has about 1000 less frequently used word family. BASEWORD 3 list is the most academic word family which are not in the most frequent word family or the most less frequently word family.

\subsubsection{Measures of sentence construction and phrase construction}

Web-based L2 Syntactic Complexity Analyzer is used to measure three indexes of sentence construction and two indexes of phrase construction. They are mean length of clause(MLC), dependent clause per clause(DC/C), complex nominal per clause(CN/C). In order to fully consider the syntactic complexity, phrase construction is also included in the scope of this study, which is explored from the density of complex noun phrases (CN/T) and the density of verb phrases (VP/T).

After the basic data came out, SPSS 22 was used to calculate the mean and standard deviation of each index. In order to analyze the fluctuations of the indexes, the line charts were formed to analyze the fluctuations of the indexes.

Finally, the three students were interviewed. Here are the interview questions:(1)What's your hardest difficulty in the process of writing? (2)whether you would consciously use more complex expressions during the process of writing? (3) Do you think that you have improved your writing? in which side?

\section{Results and Discussion}

The group average can reflect the changing trend of the tested language. And for this reason, we study the sentence complexity, phrase complexity, and lexical complexity of the group average written data of three students. 


\begin{tabular}{cllllllll}
\hline & MLCM/SD) & DC/CM/SD) & CN/C(M/SD) & LD(M/SD) & Uber(M/SD) & LS(M/SD) & CN/T(M/SD) & VP/T(M/SD) \\
\hline The 1st & $9.539 / 0.722$ & $0.290 / 0.113$ & $0.991 / 0.103$ & $0.537 / 0.029$ & $21.127 / 5.620$ & $10.629 / 1.316$ & $1.754 / 0.477$ & $2.056 / 0.342$ \\
The 2nd & $9.598 / 0.181$ & $0.426 / 0.143$ & $1.053 / 0.122$ & $0.537 / 0.439$ & $17.773 / 2.545$ & $9.920 / 0.909$ & $1.964 / 0.545$ & $2.528 / 0.409$ \\
The 3rd & $11.806 / 5.056$ & $0.422 / 0.140$ & $0.939 / 0.160$ & $0.513 / 0.017$ & $21.267 / 2.518$ & $10.764 / 1.233$ & $1.989 / 0.701$ & $2.685 / 0.883$ \\
The 4th & $9.008 / 0.312$ & $0.429 / 0.099$ & $1.114 / 0.139$ & $0.530 / 0.033$ & $22.770 / 0.391$ & $12.783 / 2.921$ & $2.512 / 0.471$ & $2.806 / 0.883$ \\
The 5th & $8.861 / 1.513$ & $0.532 / 0.119$ & $1.088 / 0.390$ & $0.553 / 0.039$ & $20.167 / 1.693$ & $7.455 / 1.681$ & $1.956 / 0.627$ & $2.230 / 0.104$ \\
The 6th & $8.913 / 1.466$ & $0.294 / 0.065$ & $0.991 / 0.264$ & $0.517 / 0.012$ & $23.233 / 3.155$ & $8.715 / 2.335$ & $1.439 / 0.460$ & $1.719 / 0.275$ \\
The 7th & $9.045 / 1.120$ & $0.376 / 0.109$ & $0.821 / 0.114$ & $0.487 / 0.021$ & $22.723 / 1.038$ & $7.840 / 0.628$ & $1.416 / 0.269$ & $2.395 / 0.212$ \\
\hline
\end{tabular}

Figure 1. The development of the eight indexes in written English complexity of the 3 participants
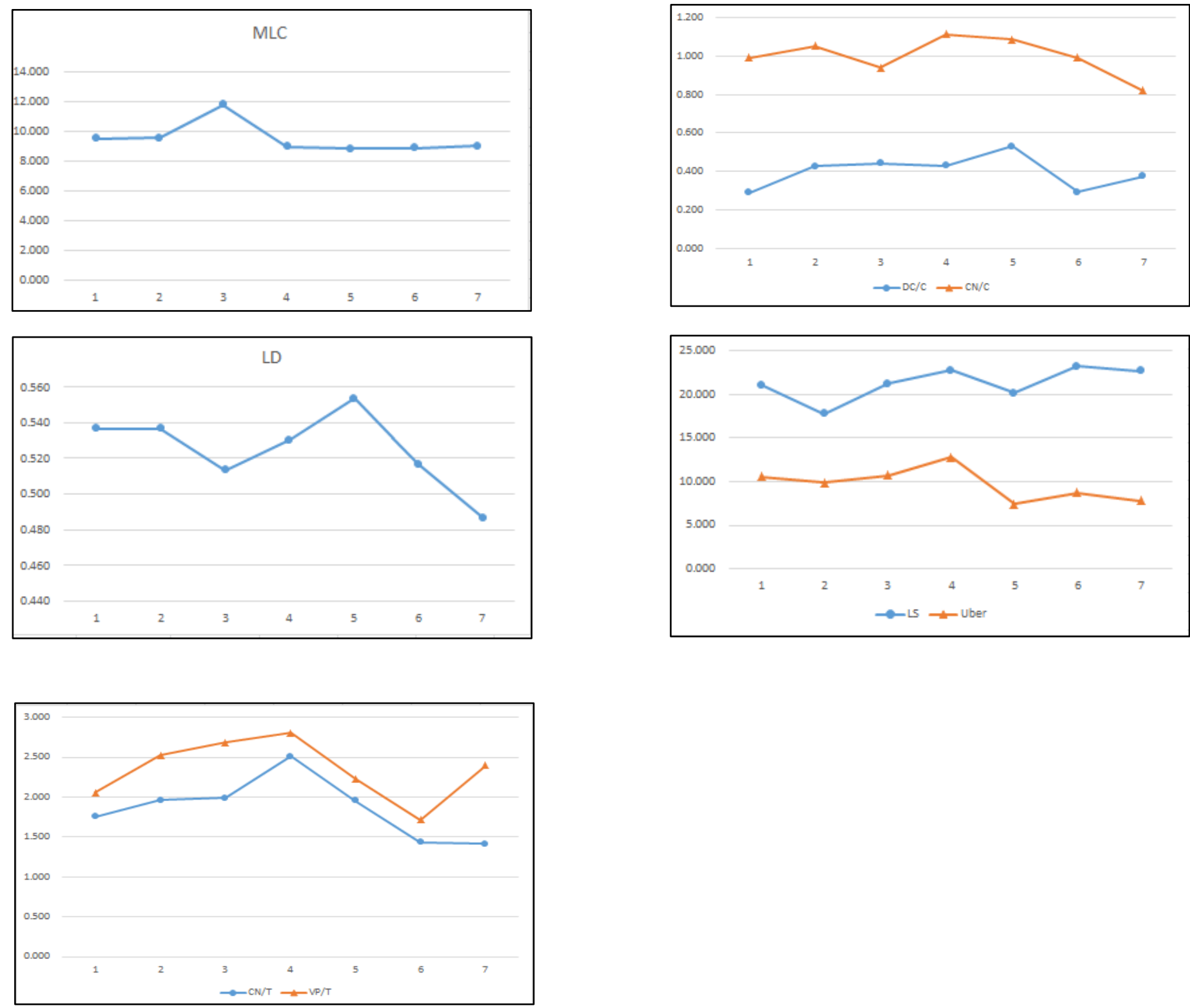

Figure 2. general development of written English complexity 
From figure 4. 2, It is obvious that the mean trajectory of the development of written language complexity is nonlinear and is accompanied by many fluctuations. In general, the process of language is full of retrogressive, stagnation and even jumping forward .It's a dynamic system behavior.

On lexical construction, In general, the index of lexical sophistication(LS) rises irregularly. lexical diversity(Uber) is linearly upward from the first writing to the fourth writing, but starts to decline in the last three writings. As for lexical sophistication(LS), the chart shows that the development of LS is not improving all the time from the first writing to the seventh writing but has fall and rise and generally decline linearly. According to Skehan's(1998) Limited Attentional Capacity Model, humans have limited information processing capacity. Thus, learners have to distribute their attention during task performance. When attention is allocated to one dimension of language production, some other dimensions might ignored. Therefore, when these students focus more on lexical sophistication, they are inevitably not able to put much attention on lexical diversity and lexical density.

With regard to syntactical construction, The mean length of clause(MLC) of the third writing moves forward a little, but it turns to its original index soon. There is no significant difference in MLC and the developmental curve is nearly flat. As for dependent clause per clause $(\mathrm{DC} / \mathrm{C})$, it undulates from the first writing to the fourth writing, and then jumps down till the end. The complex nominal per clause $(\mathrm{CN} / \mathrm{C})$ index non-linearly goes up in the first two semesters. However, it falls in the third semester.

According to the last chart of figure 4.2, the index of verb phrase per clause(VP/T) fluctuates greatly throughout the whole process. It follows the trend of moving forward, falling down and declining in the end. Complex nominal per clause $(\mathrm{CN} / \mathrm{T})$ nearly follows the same trend as $\mathrm{VP} / \mathrm{T}$ to wave and fluctuates, but the fluctuation is a little bit smaller than VP/T.

Based on the dynamic system theory, this study tracks the multidimensional development of three high-level non-English learners. From the interviews with these students, they all said that they had improved a lot after three semesters' writing. During the process of writing, they would try some complicate expressions, some focused on words, others focused on sentences. But the most difficult for them is to use what they had read or learned into practice. It proved that the development path of configurations at different levels is different, so it is necessary to be measured separately for better understanding language development. The results all show that the change and development of subjects in written complexity are not linear, but there are peaks, troughs, progress and regression. The development of written language is obvious dynamic and variable. It exactly confirms Verspoor's findings that the level of writing is always changing, and in a non-linear development situation, progress and regression alternate with each other. In addition, Studies by Zheng Yongyan(2018) have also shown that the development of written language is obvious dynamic and variable. At the same time, it is also confirmed that the complexity of the language is decomposable and needs to be measured by careful index subdivisions (Norris \& Ortega 2009).

\section{Conclusion}

How to develop learners' writing ability in foreign language environment has always been the focus of researchers and teachers. This study uses dynamic system theory to investigate the development of written language complexity of high-level English majors. In summary, the result of the present study reveals that the development of written language has obvious dynamic and variability. The process of language is full of retrogressive, stagnation and even jumping forward. Future research needs to take the above limitations into account and have a further exploration.

The present findings have important implications for language teaching in classrooms. In the teaching process, teachers should increase appropriate language input and design language output tasks in line with the level of students on the premise of output as the driver, so as to facilitate the application of receptive knowledge. At the same time, teachers should pay attention to students' individual differences, record their characteristics of language development and change, timely adjust teaching strategies, activate their accumulated knowledge in the past learning process, make their language development a continuous process, and ultimately improve the competence of English learners. Last but not least, this study also offer some helpful guidance in both learning and teaching. Students should bear in mind that the development of L2 written language is not linear, and so that there may be no progress or even decline during their learning process. There is no need to worry about a decline in language performance.

The present study has some limitations, which should be acknowledged. First of all, The interval between each writings was not uniform which may have had some effect on the findings to a certain extent. Second, All the essays were written after class, The quality of the writings is inevitable to be influenced by different factors. Last 
but not least, this study only tracks a small number of non-English majors. In the future, it is necessary to conduct dynamic research on the characteristics of second language learners of different levels for the sake of drawing more general conclusions.

\section{References}

Adele, E. G. (2003). Constructions: a new theoretical approach to language. Trends in Cognitive Sciences, 7(3), 219-224. https://doi.org/10.1016/S1364-6613(03)00080-9

Bulté, B. \& A, Housen. (2012). Dimensions of L2 Performance and Proficiency: Complexity, Accuracy and Fluency in SLA. Amsterdam: John Benjamins, 21-46. https://doi.org/10.1075/1llt.32.02bul

Bulté B. \& Housen, A. (2014). Conceptualizing and measuring short-term changes in 12 writing complexity. Journal of Second Language Writing, 26, 42-65. https://doi.org/10.1016/j.jslw.2014.09.005

Bao Gui. (2009). Study on the syntactic complexity changes of English learners' compositions. Foreign Language Teaching and Research: Foreign Language Bimonthly, (4), 291-297.

De, B. K. \& Larsen-Freeman, D. (2011). Researching second language development from a dynamic systems theory perspective. Amsterdam/Philadelphia, John Benjamins Publishing Company.

De, B. K., Lowie, W, Thorne, S. L. \& Verspoor, M. (2013). Dynamic systems theory as a comprehensive theory of second language development. Contemporary Approaches to Second Language Acquisition.

Dai Yuncai. (2015). Research on motivation of second language learning from the perspective of complex dynamic system theory. Foreign Language Studies, (6), 72-80.

Goldberg, A. (2003). Constructions: A new theoretical approach to language. Trends in Cognitive Science, 7(3), 219-224. https://doi.org/10.1016/S1364-6613(03)00080-9

Larsen-Freeman, D. \& Cameron, L. (2008). Complex systems and applied linguistics. Oxford: OUP.

Larsen-Freeman, D. (2006). The emergence of complexity, fluency, and accuracy in the oral and written production of five Chinese learners of English. Applied Linguistics, 27(4), 590-619.https://doi.org/10.1093/applin/aml029

Lu Xiaofei. (2010). Automatic analysis of syntactic complexity in second language writing. International Journal of Corpus Linguistics, 15(4), 474-496.https://doi.org/10.1075/ijcl.15.4.02lu

Li Langxia. (2011). Dynamic System Theory and Second language development. Foreign Language Teaching and Research, (3), 409-421.

Marianne, S. \& Verspoor, M. (2010). Dynamic patterns in development of accuracy and complexity: a longitudinal case study in the acquisition of finnish. Applied Linguistics, 31(4), 532-553. https://doi.org/10.1093/applin/amq001

Ortega, L. (2003). Syntactic complexity measures and their relationship to 12 proficiency: a research synthesis of college-level 12 writing. Applied Linguistics, 24(4), 492-518. https://doi.org/10.1093/applin/24.4.492

Scott, F. B. \& William, E. N. (2009). Syntactic complexity as a predictor of adolescent writing quality: which measures? Which genre? Reading \& Writing, 22(2), 185-200. https://doi.org/10.1007/s11145-007-9107-5

Verspoor, M. \& Behrens, H. (2011). Dynamic systems theory and a usage based approach to second language development. Journal of Environmental Chemical Engineering, 335(1), 565-573.

Verspoor, M., Schmid, M. \& Xu. (2012). A dynamic usage based perspective on 12 writing. Journal of Second Language Writing, 21(3), 239-263. https://doi.org/10.1016/j.jslw.2012.03.007

Wolfe-Quintero, K., Inagaki, S. \& Kim, H. Y. (1998). Second language development in writing: measures of fluency, accuracy and complexity. Honolulu: University of Hawaii Press.

Wang Chuming. (2015). Construction and Construction Context and Second Language Learning. Modern Foreign Languages, 38(3), 357-365.

Wang Haihua, Li Beibei, \& Xu Lin. (2015). A Case Study on the development of written language proficiency of Chinese EnglishlLearners. Foreign Language Teaching and Research, (1), 67-80.

Xu Chunyan, Zhang Jun, \& Zhan Ju. (2017). Study on the Complexity, Accuracy and Fluency of students' English compositions in transnational interactive writing courses from the perspective of Dynamic System Theory. Chinese Foreign Languages, (6).

Zheng Yongyan. (2017). Research on complexity development of second language written syntax based on 
tracing cases. China Foreign Language Education.

Zheng Yongzheng. (2011). Application of Dynamic System Theory in the study of Second Language Acquisition-Taking the study of second language vocabulary development as an example. Modern Foreign Languages, 33(3), 303-309.

Zheng Yongyan, \& Feng Yuli. (2017). Dynamic systematic study of learners' syntax and vocabulary complexity development. Modern Foreign Languages, (1), 57-68.

\section{Copyrights}

Copyright for this article is retained by the author(s), with first publication rights granted to the journal.

This is an open-access article distributed under the terms and conditions of the Creative Commons Attribution license (http://creativecommons.org/licenses/by/3.0/). 